\title{
Introducción al Caribe: \\ Dominación y fragmentación colonial
}

Frank Moya Pons

FondoMicro. República Dominicana

Panorama de la organización colonial del Caribe en el que se revisa la distribución de las islas entre los países europeos. Las posesiones de España, Inglaterra, Francia y Holanda aparecen comentadas en sus avatares históricos, valorándose el auge y la decadencia de la esclavitud, hasta llegar a la abolición. junto a la evolución de sus respectivos sistemas coloniales.

El Caribe es el archipiélago más fragmentado del planeta. Esta fragmentación no es el resultado de la geografía, sino de la dominación colonial. En el siglo XVI, España apenas logró colonizar las cuatro Antillas mayores (Cuba, Santo Domingo, Jamaica y Puerto Rico) pues las pequeñas Antillas no tenían oro y fueron consideradas desde temprano como "islas inútiles" por los conquistadores.

El interés por el oro y la plata de México y Perú desvió pronto la atención de los españoles hacia el continente. Las islas quedaron entonces semi-abandonadas, aunque bajo el control de guarniciones militares que impidieron que Francia, Inglaterra y Holanda pudieran ocupar la grandes Antillas. Jamaica fue la única excepción ya que fue tomada por los ingleses en 1655 y nunca más volvió a cambiar de manos.

Durante el siglo XVII, las pequeñas Antillas fueron ocupadas y colonizadas por Francia, Inglaterra y Holanda para ser convertidas, primero, en colonias productoras de tabaco $\mathrm{y}$, más tarde, en plantaciones azucareras que funcionaban sobre la base de la mano de obra esclava. Así, en 1625, Barbados y San Cristóbal cayeron en manos inglesas, en tanto que Curaçao y Aruba fueron ocupadas por holandeses en 1630, de la misma manera que Guadalupe y Martinica cayeron en manos francesas en 1635. Más adelante, en el siglo XVIII, Dinamarca compró a Francia la isla de St. Croix y la convirtió también en una colonia azucarera, conjuntamente con las islas de St. Thomas y St. John.

En los siglos XVII y XVIII, ingleses, franceses y holandeses se disputaron el control de las pequeñas Antillas, de tal manera que algunas cambiaron de manos varias veces durante las guerras. La historia de esas 
ocupaciones, desalojos y reocupaciones es larga y terminó imprimiendo un sello colonial particular a las islas. Al concluir las guerras napoleónicas en 1814, las Antillas quedaron definitivamente alineadas en distintos bloques coloniales y no volvieron a cambiar de dueño (con excepción de Santo Domingo que retornó brevemente al dominio español entre 1861 y 1865).

Cuba y Puerto Rico quedaron bajo control español. St. Croix, St. Thomas y St, John permanecieron dominadas por Dinamarca. Jamaica, Trinidad, Tobago, Barbados, Dominica, St. Lucia, Grenada y las Grenadinas, St. Kitts, Monserrat, Nevis, Antigua, Anguila, Barbuda y Tórtola, quedaron bajo dominio británico. Curaçao, Aruba, Bonaire, St. Marteen, Saba y St. Estache permanecieron bajo control holandés; en tanto que Guadalupe y Martinica quedaron bajo dominio francés.

La única excepción a este cuadro de colonias caribeñas en el siglo XIX lo constituyó la isla de Santo Domingo. Esta isla quedó dividida en dos repúblicas independientes, Haití y República Dominicana, que se formaron sobre las cenizas de la conflagración producida por las revoluciones francesa y haitiana. Haití obtuvo su independencia de Francia en 1804, y Santo Domingo de España en 1821. Sin embargo, los haitianos invadieron la parte española de la isla en 1822 y la dominaron durante 22 años. Por eso la República Dominicana vino a alcanzar su independencia en 1844.

Es importante tener en cuenta estos contrastes pues en los años en que Gran Bretaña, Francia, Dinamarca y España debatían sobre el futuro de la esclavitud en las islas, ya en Haití y Santo Domingo existían dos estados que la habían extinguido décadas antes, y se organizaban según los modelos constitucionales republicanos de Francia y los Estados Unidos. En ambos casos, los antiguos esclavos obtuvieron tierras y se convirtieron en campesinos independientes.

El ejemplo político y constitucional de la isla de Santo Domingo dio lugar a importantes movimientos políticos en Cuba y Puerto Rico que tuvieron como metas la abolición de la esclavitud y el logro de la independencia política. Esos movimientos fueron reprimidos sistemáticamente por las autoridades españolas, que buscaron en todo momento preservar tanto la esclavitud como la dominación colonial en las islas.

La primera guerra de independencia cubana fracasó después de 10 años de lucha, entre 1868 y 1878 , pero el avance del movimiento abolicionista en la misma España contribuyó a liquidar la esclavitud en Puer- 
to Rico en 1875, y en Cuba en 1886. Una segunda guerra de independencia iniciada en 1895 por los nacionalistas cubanos arrastró a los Estados Unidos al conflicto en 1898. La intervención norteamericana en ambas islas produjo la llamada Guerra Hispano-Americana que dio como resultado la terminación del dominio español en Cuba, Puerto Rico y las Filipinas.

Esta guerra marca la culminación de un largo proceso de penetración norteamericana en el Caribe que se inició mucho antes de la independencia de los Estados Unidos. A medida que Cuba y Puerto Rico se fueron convirtiendo en colonias azucareras en el siglo XIX, los Estados Unidos fueron también desplazando gradualmente a España como compradores de azúcares y mieles, y abastecedores de maderas, harinas, pescado seco, carnes ahumadas, y artículos de ferretería. Tan importantes fueron las conexiones entre Cuba y los Estados Unidos que tanto en esa isla como en Norteamérica se formaron varios movimientos políticos para tratar de anexar la isla a los Estados Unidos. Algo similar, pero con menor intensidad, ocurrió también en Puerto Rico.

La lucha por la descolonización de Cuba y Puerto Rico se vio obstaculizada por los conflictos internos norteamericanos en torno a la abolición de la esclavitud, y por los intereses azucareros norteamericanos que buscaban impedir la entrada libre de impuestos de los azúcares cubanos al mercado estadounidense. La anexión de Cuba y de Puerto Rico a los Estados Unidos fue un proyecto largamente acariciado por importantes sectores políticos norteamericanos y cubanos, pero los poderosos intereses azucareros obstaculizaron su materialización. Por esta razón, cuando España fue despojada de sus dos últimas posesiones coloniales en las Antillas en 1898, Cuba no pudo ser anexada formalmente a los Estados Unidos.

Tampoco pudieron Cuba y Puerto Rico alcanzar de inmediato su plena independencia y ambas islas permanecieron en una situación de dependencia anómala. Los nacionalistas cubanos lograron que les fuese reconocida su independencia, aunque la misma quedó seriamente limitada en 1903, a partir de la imposición de la famosa Enmienda Platt. Los puertorriqueños, en cambio, no tuvieron la misma capacidad de negociación y su territorio quedó convertido en una posesión de ultramar de los Estados Unidos, con un status político indefinido. Un status similar al de Puerto Rico se les impuso a las Islas Vírgenes danesas cuando les fueron compradas a Dinamarca por los Estados Unidos en 1917, en medio de la Primera Guerra Mundial. 
Las colonias británicas, entretanto, evolucionaron en forma diferente en el siglo XIX. Bajo el control de legislaturas locales controladas por los plantadores blancos, o bajo el control de funcionarios coloniales directamente dependientes de la Oficina Colonial de la Gran Bretaña. las colonias británicas no dieron muestras de estar interesadas en la independencia, a pesar de que el gobierno británico prohibió el comercio de esclavos a partir de 1807, y decretó la abolición de la esclavitud en 1834, la cual se hizo efectiva en 1838 después de un período de transición o aprendizaje para los libertos que duró cuatro años.

En las décadas siguientes a la abolición de la esclavitud, los plantadores blancos y las asambleas coloniales dominadas por ellos, realizaron numerosas maniobras legislativas, políticas y judiciales para mantener a sus antiguos esclavos atados a las plantaciones. El éxito de esos esfuerzos varió según las colonias, y según el tamaño de las islas y la cantidad de tierras disponibles para asentar a los libertos.

Para reponer la mano de obra perdida a consecuencia de la abolición, los plantadores de casi todas las islas, incluyendo las colonias francesas, importaron mano de obra servil contratada en la India, China y Africa Occidental, y hasta en Portugal y Alemania. Los mayores flujos de trabajadores contratados procedieron de las regiones más deprimidas de la India y China. Esta inmigración asiática tuvo como consecuencia inmediata la devaluación de los salarios y el empeoramiento de las condiciones de trabajo en las plantaciones.

La abolición de la esclavitud también trajo consigo la regeneración del crecimiento demográfico de la población de origen africano y, en consecuencia, el empeoramiento de las condiciones de vida de la población. La abolición también hizo posible la formación de una capa social media compuesta por mulatos más o menos educados que, apoyados por las iglesias locales, reclamaban un cambio de política en las colonias que sirviera para mejorar las condiciones de vida de la población.

La Gran Bretaña no respondió decisivamente a estos reclamos hasta después de la importante rebelión de Morant Bay, ocurrida en 1865, en un poblado de Jamaica que lleva ese nombre. Esta rebelión sirvió de catalizador para impulsar los primeros cambios políticos y constitucionales importantes en las colonias británicas desde los siglos XVII y XVIII. A consecuencias de las reformas impuestas por la Gran Bretaña, las asambleas coloniales perdieron sus poderes y las islas quedaron convertidas en "colonias de la Corona" o Crown Colonies. 
La creación del sistema de "colonias de la Corona" tomó varios años pues no todas las oligarquías coloniales acogieron favorablemente las presiones del gobierno británico para quitar poder a las asambleas coloniales y traspasarlo a los gobernadores nombrados en Londres. Las élites blancas de Barbados, las Bahamas y Bermuda resistieron y conservaron sus viejas asambleas coloniales, que estaban compuestas por representantes electos por los propietarios blancos y la gente adinerada de las colonias.

Las demás islas terminaron el siglo XIX con un gobierno colonial mucho más centralizado, y con una dirección política más dependiente de la Oficina Colonial Británica. En la medida de lo posible, los nuevos gobernadores de las "colonias de la Corona" evitaron responder exclusivamente a los intereses de los plantadores blancos, y trataron de gobernar en favor de toda la comunidad colonial. Esta era, desde luego, una aspiración más que una realidad pues el control de la economía azucarera quedó en las mismas manos. Aun así, los gobiernos coloniales centraron su atención en la construcción de caminos y otras obras de infraestructura que habían sido descuidadas por las asambleas coloniales.

Bajo el sistema de las Crown Colonies las nuevas autoridades mejoraron las facilidades educativas y de salud en algunas islas. Siguiendo las recomendaciones de varias comisiones que investigaron las deplorables condiciones sociales de las colonias, los gobiernos coloniales detectaron tierras públicas y las pusieron a la venta, de manera que los libertos pudieran convertirse en campesinos y tuvieran la oportunidad de emanciparse de las plantaciones.

El sistema de las Crown Colonies dominó políticamente la vida del Caribe británico hasta después de la Segunda Guerra Mundial. Bajo este sistema, los habitantes de las islas no tenían derecho a elegir a los nueve miembros del Consejo Legislativo colonial compuesto por cuatro funcionarios coloniales que actuaban ex-oficio y por cinco individuos de la sociedad civil elegidos directamente por el gobernador. Las únicas modificaciones significativas que sufrió el sistema colonial en el siglo XIX fueron los aumentos en el número de miembros del Consejo. En 1895, los Consejos Legislativos subieron de 9 a 29 miembros para dar mayor participación a los diversos sectores de la sociedad colonial.

Al comenzar el siglo XX, las presiones en favor de la inclusión de miembros electos por voto popular empezaron a hacerse sentir en las islas. Solamente después de una investigación realizada en 1921, fue que 
el gobierno británico consintió en permitir la inclusión de miembros electos en los Consejos Legislativos. Así, a partir de 1925, se empezó a dar cabida a tres miembros elegidos por un limitado electorado compuesto por los propietarios, rentistas y asalariados que podían justificar bienes valorados en más de 5 libras esterlinas o ingresos anuales mayores de 50 libras esterlinas. Para 1936, la mayoría de los Consejos Legislativos de las Antillas británicas tenían tres de sus miembros electos, pero el poder que estos individuos tenían para influir en las decisiones era prácticamente nulo.

La evolución política colonial de las islas francesas difiere de la experiencia británica en las Antillas, pero el régimen colonial francés, al igual que el británico, también enfatizó el absolutismo del poder metropolitano. Así, la población de las islas quedó también marginada de los movimientos independentistas de las islas españolas. Francia, por ejemplo, convirtió a Guadalupe y Martinica en Crown Colonies a partir de 1815, una vez que la monarquía fue restaurada a la caída de Napoleón Bonaparte. El concepto subyacente en esta decisión era que las colonias eran patrimonio de la Corona y debían ser gobernadas directamente por ella.

Durante todo el siglo XIX Guadalupe y Martinica fueron regidas en forma casi absoluta por gobernadores asistidos por un Consejo consultivo compuesto por funcionarios nombrados directamente por la Corona. A partir de 1848, la revolución liberal triunfante otorgó a las colonias el derecho a la representación directa en el Parlamento francés, y concedió a los colonos el derecho a la ciudadanía francesa. El gobierno absoluto de Napoleón III, que rigió Francia entre 1852 y 1870, abolió el derecho de representación, pero la Tercera República reinstauró este derecho de nuevo, poniendo así en marcha un proceso de asimilación de las colonias a la metrópoli que dura hasta nuestros días.

Al igual que en las colonias británicas, las Antillas francesas pasaron por un proceso de agitación abolicionista que culminó con la abolición de la esclavitud en 1848. También en Martinica y Guadalupe los plantadores tuvieron que recurrir a la importación de trabajadores contratados en la India para llenar el vacío dejado por los libertos que salieron de las plantaciones. $\mathrm{Y}$ al igual que en las islas más grandes, como Jamaica y Trinidad, muchos libertos encontraron tierras de la Corona en donde se establecieron con sus familias y comenzaron a vivir como campesinos independientes de las plantaciones. 
El sistema de gobierno directo de la Corona se mantuvo vigente hasta el final de la Segunda Guerra Mundial. Entonces, las presiones anticolonialistas y la agitación democrática francesa forzaron al gobierno de París a otorgar el derecho a voto a los individuos a quienes Francia había reconocido su ciudadanía desde tiempo atrás. Como culminación de este proceso de asimilación, en 1946 Francia convirtió a Martinica, Guadalupe y la Guayana Francesa en Prefecturas de Ultramar con derecho a enviar tres miembros representantes a la Asamblea Nacional Francesa en París. Esta importante reforma cambió las funciones del antiguo gobernador, que a partir de entonces fue llamado prefecto, y otorgó a los habitantes de las colonias el derecho a elegir directamente a los miembros de un Consejo General colonial con funciones consultivas y administrativas.

En cuanto a las colonias holandesas en el Caribe, debe recordarse que Curaçao, Aruba y Bonaire habían sido colonizadas por la antigua Compañía de las Indias Occidentales en la primera mitad del siglo XVII, y que esta compañía había mantenido el control de estas islas y las había convertido en centros de distribución de mercancías que se vendían de contrabando en otras partes del Caribe y la América hispana. El gobierno de estas islas cambió en 1828 cuando la Corona holandesa se hizo cargo de su administración directa y las convirtió en Crown Colonies manejadas por un gobernador y sin representación directa.

En las colonias holandesas la cuestión colonial reflejó también las reformas políticas liberales introducidas en varias partes de Europa a consecuencia de la revolución de 1848. A medida que el Parlamento holandés fue ganando terreno políticamente, en esa misma medida avanzó la idea de que las Antillas holandesas debían tener sus propias estructuras de representación y participación política.

Así, en 1865, la situación cambió sustancialmente pues el Parlamento holandés decretó la creación de una Asamblea colonial que debía asistir al gobernador. Esta Asamblea, sin embargo, no sería elegida por los colonos, pues sus miembros los nombraría el mismo gobernador de entre la élite colonial. A pesar de las protestas y discusiones generadas momentáneamente por esa decisión, los habitantes de las Antillas holandesas aceptaron la decisión y fueron regidos por este tipo de sistema colonial hasta después de la Segunda Guerra Mundial.

Como se ve, el Caribe llega a la mitad del siglo XX completamente fragmentado en bloques de islas dominados por varias potencias me- 
tropolitanas que poseían territorios coloniales en otras partes del planeta. La gran depresión económica mundial de los años 30 empeoró las condiciones de vida en todas las colonias y contribuyó a exacerbar las tendencias anticolonialistas de algunos intelectuales y políticos que demandaban mayor apertura y participación política, incluyendo el derecho a formar sindicatos y partidos políticos, así como el derecho a elegir sus propios gobernantes. 